\title{
UNRUPTURED INTRACRANIAL ANEURYSM PRESENTING WITH EPILEPTIC SEIZURE
}

\author{
José C. Sena ${ }^{1}$, Yves Reynier ${ }^{2}$, Bernard Alliez²
}

\begin{abstract}
Intracranial aneurysms are frequently present with subarachnoid hemorrhage.Less often they produce suggestive symptoms of cranial nerve dysfunction or intracranial tumor when very large. Their association with epilepsy has rarely been reported; such concurrence may not be a coincidence. When the patient presents with epileptiforme attacks the presence of an intracranial aneurysm is rarely considered. In this paper we report the case of a 45 -years-old patient with an unruptured aneurysm of the middle cerebral artery with a 10 years history of epileptic seizure.
\end{abstract}

KEY WORDS: intracranial aneurysm, epilepsy, middle cerebral artery, giant aneurysm.

\begin{abstract}
Epilepsia secundária a aneurisma cerebral não roto
RESUMO - Aneurismas intracranianos freqüentemente se apresentam com hemorragia subaracnóidea quando rotos, porém quando gigantes sangram com menor freqüência e se comportam como verdadeiros tumores, comprimindo estruturas cerebrais adjacentes, apresentando sintomatologia peculiar. Relatamos o caso de um paciente de 45 anos que apresentava crises convulsivas generalizadas com evolução de 10 anos. A investigação radiológica revelou presença de aneurisma gigante da artéria cerebral média, não roto. É realizada revisão da literatura correlacionando a presença de aneurismas não rotos e epilepsia, pois esta associação é pouco freqüente na literatura.
\end{abstract}

PALAVRAS-CHAVE: aneurisma intracraniano, epilepsia, artéria cerebral média, aneurisma gigante.

An unruptured aneurym can come to clinical attention in a variety of ways including mass effect, headaches embolic events and seizures. Although it has been recognized for many years that unruptured cerebral aneurysm may cause epilepsy, this is not common $^{1-5}$. The most frequent causes of seizures are: cerebrovascular disease $13.2 \%$, developmental disorders $5.5 \%$, head trauma $4.1 \%$, brain tumors $3.6 \%$, central nervous system (CNS) infection $2.6 \%$, degenerative CNS diseases $1.8 \%$, and for the remaining (70\% of the cases) the etiology are unknow. Aneurysms which cause epilepsy are usually large, and situated on the middle cerebral artery ${ }^{6-9}$. Frankel and Alpers ${ }^{10}$ describe one patient with a giant aneurysm of the middle cerebral artery, who had presented with complex partial seizures that had persisted for the 3 years prior to her death after aneurysmal surgery. In Bull's ${ }^{7}$ series 4 out of 22 giant intracranial aneurysms presented initially epilepsy and among 666 patients with seizures reported by Currie et al. ${ }^{11}$, only one had an unruptured intracranial ane- urysm of the middle cerebral artery. Solomon et al. ${ }^{12}$ reported epilepsy in 10 out of 202 unruptured intracranial berry aneurysms located outside cavernous sinus. Seizures can preced discovery of the aneurysm by many years. Seizures disorders of many year's duration are also described in the series of Drake ${ }^{13}$. Aneurysms can produce seizures by a number of mechanisms, including compression or infarction of adjacent brain tissue as well irritation of the underlying cortex $^{14,15}$.

We report a 45-year-old left-handed white man, in the previous 10 years he had frequent seizures with an aura, in which he felt an unpleasant taste in his mouth, dizziness and subsequent falling. In spite of anticonvulsant therapy, the attacks became more frequent, and the patient developed an aggressive personality; a computed tomography scan revealed a much larger contrast enhancing mass in the rigth temporal lobe, and carotid angiography showed there was a large aneurysm arising from the right middle cerebral artery. In contrast to the ruptured aneurysm,

${ }^{1}$ Centre Hospitalier de la Côte Basque - Bayonne, France; ${ }^{2}$ Centre Hospitalier Universitaire de Marseille, France.

Received 11 September 2002, received in final form 29 January 2003. Accepted 18 February 2003. 


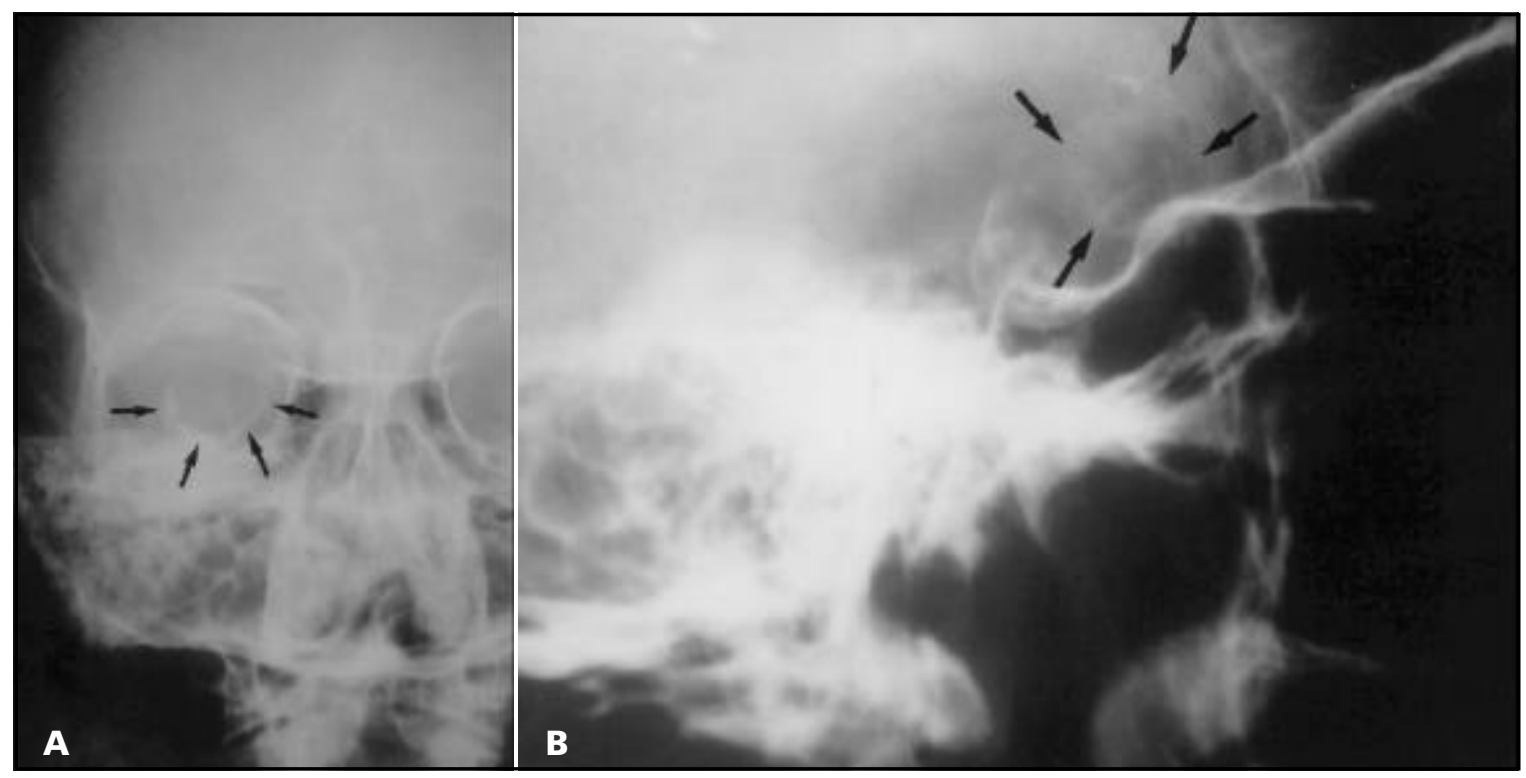

Fig 1 (A and B). Plain skull film showing curvilinear calcification (arrows).

reports concerning seizure in the unruptured group are rare. The relevant literature on aneurysm as a cause of epilepsy is reviewed.

\section{CASE}

A 45-year-old left-handed, white man, without history of alcool abuse, was admitted to the emergency room after a generalized tonic-clonic seizure with inconsciousness, tongue biting and urinary incontinence. He remained inconscious for twenty minutes and did not complain of any headache, nausea or vomiting, but he had generalized fatigue. He was amnestic for the episode but he remembered all events up to and immediately after the event. His family said that over the previous 10 years he had experience many similar episodes and that during the 6 months before admission there had been a definite general deterioration in his memory. There was no past history suggestive of a prior subarachnoid hemorrhage or transient ischemic events. On examination, he was alert and behaving normally, but was unable to understand any written or spoken language and was unable to say anything apart from "yes" and "no". There was no sign of meningism. General physical examination showed normal results. Routine laboratory tests were negative. Over the next 3 hours, his language function gradually returned to normal.

On specific questioning he remembered that he had had several episodes beginning with a peculiar sensation spreading from abdomem to the chest associated with bad taste in his mouth lasting several minutes, sweating on the forehead and the sense of voices sounding distorded and distant followed of dizziness and subsequent falling and seizure. In spite of anticonvulsivant therapy, the attacks became more frequent and the patient developed an aggressive personality.
A large oval calcification was found in the rigth temporal region on the plain skull film (Fig 1). Severe disturbance in the rigth hemisphere, with some sharp wave discharge over the right temporal area were found on conventional electroencephalogram. A computed tomography scan (CT) revealed an ovoide contrast-enhancing mass of the rigth temporal lobe (Fig 2). A four vessel retrograde femoral arteriogram demonstrated a large aneurysm arising from the middle cerebral artery (Fig 3).

Although there was no history of subarachnoid hemorrhage it was decided that aneurysm should be clipped because anecdotal cases of incidental aneurysms left untreated that subsequently ruptured are well known. The patient underwent a right fronto-temporal craniotomy. No evidence of hemorrage products was found within the surrounding subarachnoid space on adjacent brain to indicate prior rupture. A partially thrombosed aneurysm of the middle cerebral artery was confirmed. The aneurysm was excised after clipping of its neck.

The patient had an uneventful recovery, and was discharged home on a regimen of $1200 \mathrm{mg}$ of carbamazepine daily for 24 months. He has been followed for 5 years and has been seizure-free since the intervention.

\section{DISCUSSION}

Seizure is one of the oldest recorded medical conditions. The earliest written reference to epilepsy can be found in the Babylonian code of Hammurabi (Louvre Museum, Paris) written in the 17 th century BC. One of the clauses in the code specifies that the person buying a slave had the rigth to return him/ her within one month of being bought if he/she had epilepsy. Galen, in 375 AD, distinguished between seizures originating in the brain and those that had 


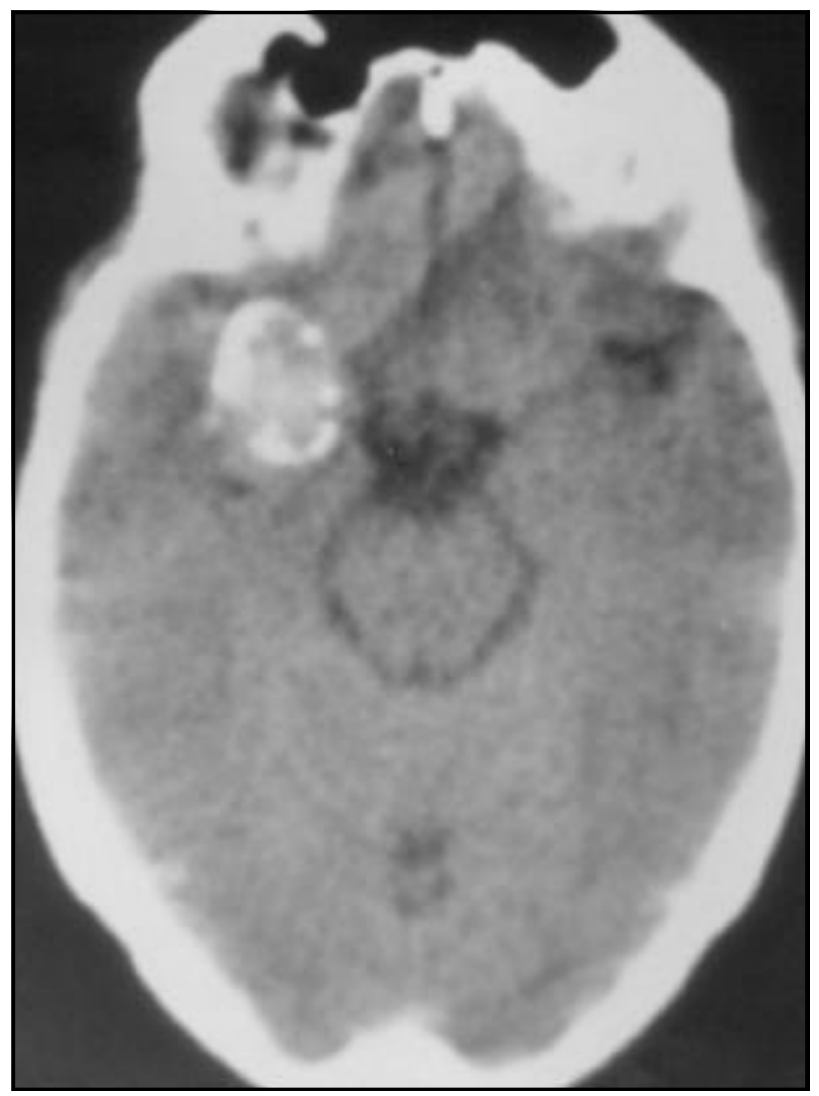

Fig 2. Contrast-enhanced axial CT demonstrating large right temporal mass.

their anatomical origin elsewhere in the body, and designated the former as idiopathic and the latter as symptomatic.

Seizure is a symptom, not a disease. Seizures can be symptomatic of a brain tumor, brain abscess, encephalitis, meningitis, metabolic disturbance, drug intoxication, drug withdrawal and unruptured cerebral aneurysm. Although it has been recognized for many years that cerebral aneurysm may cause seizure, when the patient presents with seizures, the presence of a giant unruptured intracranial aneurysm is rarely considered ${ }^{3}$. Giant intracranial aneurysms have been defined as those over $25 \mathrm{~mm}$ in diameter; approximately $5 \%$ of all intracranial aneurysms are more than $25 \mathrm{~mm}$ in diameter. These giant intracranial aneurysms behave differently from smaller aneurysms and pose different problems in management $3,5,6,9,11,16-21$. In some large series of giant unruptured intracranial aneurysms the majoritary present with signs of a mass lesion; there is a prevailing opinion that giant aneurysms seldom rupture; only $40 \%$ of giant aneurysms present with subarachnoid hemorrhage; the other $60 \%$ may cause diagnostic difficulties when present in one of the following ways: as a slowly enlarging intracranial mass causing progressive cranial nerve, brainsten, or cerebral hemispheric disfunction; as transient ischemic attacks or cerebral infarction, as progressive dementia with or without feactures of diencephalic amnesia and seizures ${ }^{5,13}$.

Our case surviving patient had seizures for ten years without clinical subarachnoid hemorrhage may be added to other cases in the literature in which recurrent seizures occurred for many years without clinical manifestations of subarachnoid hemorrhage from the giant aneurysms. In the collaborative aneurysms study reported by Locksley ${ }^{22,23}$ only $4 \%$ of the 2.621 patients who had a first subarachnoid hemorrhage had seizure before bleeding. In 151 cases of unruptured aneurysms, seizure was detected in $36 \%$ of the middle cerebral artery and $8 \%$ of the posterior communicating cerebral artery.

Morley and Barr ${ }^{24}$ described 28 patients with giant aneurysms, 3 had seizures.Two of them had seizures for many years before undergoing operation for the occlusion to the neck of the aneurysm.In all patients the aneurysms were located at the middle cerebral artery. In a survey of 21 cases of giant aneurysms, Liang-fu and Da-Jie ${ }^{25}$ reported epilepsy in 2 cases, both located at the middle cerebral artery. Sengupta et al. ${ }^{26}$ reported 6 cases of seizures and unruptured aneurysm. In all cases, the aneurysms were located at the middle cerebral artery. The interval between onset of seizures and diagnosis varied from 1 day to 30 years.

The types of seizure vary from generalized to focal and temporal lobe attacks ${ }^{14,27-40}$. Despite great advances in the surgical, endovasculaire, and medical management of patients with aneurysmal subarachnoid hemorrhage, the morbidity and mortality rates associated with this disease remain unacceptably high. Only about $50 \%$ of patients admitted to neurosurgical centers with the diagnosis of aneurysmal subarachnoid hemorrhage have a good outcome ${ }^{12}$. The solution of the problem is to diagnose and treat aneurysms prior to rupture. But, can aneurysms be identified before rupture? Locksley ${ }^{22,23}$ reported that only 10 to $15 \%$ of aneurysms cases present the opportunity for diagnosis before rupture. Internal carotid aneurysms (especially those at the posterior communicating or ophthalmic junction) have the greatest propensity for producing symptoms prior to rupture; aneurysms in the region of the internal carotid-posterior communicating junctions in $8 \%$ had seizures, on the other hand $36 \%$ of middle cerebral aneurysms presented with seizures ${ }^{39,40}$. It is not obvious how giant aneurysms of the middle cere- 


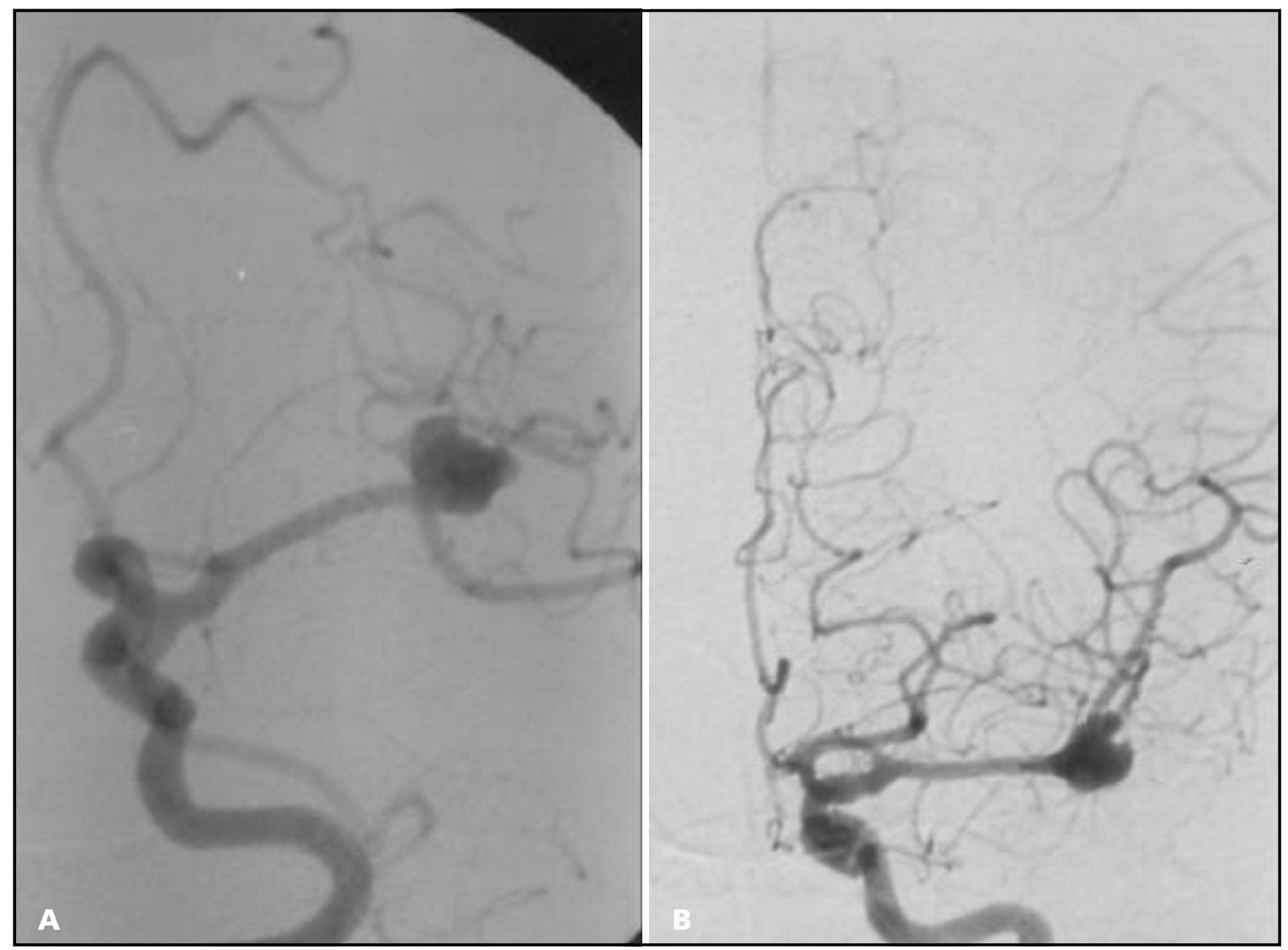

Fig 3 (A and B). Arteriograme demonstrates middle cerebral artery aneurysm.

bral artery cause epileptic seizures, some hypotheses may be postulated: compression and infarction of temporal lobe structures seem important. The mesial temporal lobe structures have a low seizure threshold and are particularly epileptogenic if damaged. Minor leakages from the adventitia of the giant aneurysmal fundus may produce localized damage to be brain and act as epileptogenic foci; transient or permanent focal disturbances in blood flow to the temporal lobe could be caused by aneurysm of the middle cerebral artery in several ways. The anterior temporal or temporal-polar artery ostia could be mechanically occluded or hemodynamically compromised by the aneurysm or flow disturbances emanating from it. Intraaneurysmal thrombus or vasoconstrictor substances such as tromboxane $A 2$ and prostaglandin $A 2$, both of which may be formed in an aneurysm, may embolize distally along either of the vessels supllying the temporal lobe. These vascular phenomena may aggravate the seizure tendency caused by the mass effect on giant aneurysm ${ }^{8,32,33}$.

The natural history of the accidentally discovered aneurysms is not know. However of the 34 cases of unruptured aneurysms treated non-surgically in the cooperative study by Sahs et al. ${ }^{15}, 9$ cases or $26 \%$ eventually had a fatal subarachnoid hemorrhage. At the present time, there is no way to predict with certainty which patients with unruptured aneurysm are in imminent danger. Therefore, if an appropriate low-risk procedure can be offered, all young healthy patients with incidental aneurysms should be treated $^{12}$. Recurrent convulsive attacks in a patient harboring an aneurysm may precipitate its rupture, accordingly, seizure may be a warning sign of a major rupture. Therefore, it is justifiable to treat these aneurysms to prevent a future rupture ${ }^{15,26,34,35}$.

Magnetic resonance (MR) imaging examination is essential in evaluation of patients with seizures and unruptured intracranial aneurysm - abnormal perianeurysmal MR signal, may indicate that the aneurysm is not an incidental finding but related to the cause of the seizure ${ }^{8,41}$.

We conclude that a diagnosis of cryptogenic epilepsy should be made only when every possible etiologic factor has been eliminated although patients should be carefully investigated and followed to determine the basis of the seizures it 
should be recognized that in at least $50 \%$ of patients who have epileptic seizures without other abnormal findings, no destructive lesion of the brain will develop ${ }^{6}$.

Acknowledgements - We wish to thank Mrs De Conto Sena for assistance in the preparation of this paper.

\section{REFERENCES}

1. Calvário JS, Aspesi NV, Kerhwald MA, Cunha RS. Epilepsia de início tardio. Proceedings of fourth annual meeting of the Associação Médica do Estado do Rio Grande do Sul. Porto Alegre (Brasil), 1983:15.

2. Calvário JS, Late onset epilepsy. F Méd (BR) 1989;99:73-74.

3. Gowers WR, A manual of diseases of the nervous system. 2.Ed. Philadelphia: Blakiston, 1898,2:533.

4. Oka H, Kurata A, Miyasaka Y, et al. Completely thrombosed large aneurysm of the distal middle cerebral artery: a case report. No Shinkei Geka 1994;22:677-680.

5. Sonntag VKH, Yuan RH, Stein BM. Giant intracranial aneurysms: a review of 13 cases. Surg Neurol 1977;8:81-83.

6. Annegers JF. The epidemiology of epilepsy. In Wyllie E (ed). The treatment of epilepsies: principles and practice. Philadelphia: Lea \& Febiger, 1993:157.

7. Bull J. Massive aneurysms at the base of the brain. Brain 1969;92:535-537.

8. Prandini MN. Epilepsia por aneurisma cerebral. Ars Cvrandi 1978;7:68-76.

9. Witoonpanich R, Bunyaratavej S, Vejjajiva A. Epileptic seizures in intracranial aneurysm. J Med Ass Thailand 1980;63:192-194.

10. Frankel K, Alpers BJ. The clinical syndrome of aneurysms of the middle cerebral artery. Arch Neurol Psychiatry 1955;74:46-67.

11. Currie S, Heathfield WG, Henson RA, Scott DF. Clinical course and prognosis of temporal lobe epilepsy. Brain 1971;94:173-190.

12. Solomon RA, Fink ME, Pille-Spellman J. Surgical management of unruptured intracranial aneurysms. J Neurosurg 1994;80:440-446.

13. Drake CG. Giant intracranial aneurysms: experience with management in 174 cases. Clin Neurosurg 1979;6:12-95.

14. Oliveira SV, Roca GR, Veiga JCE, Leal FSCB, Guapo AC. Partial complex seizures associated with unruptured giant intracranial aneurysm. Arq Bras Neurocirurg 1989;8:163-167.

15. Sahs AL, Perret GE, Locksley HB, Nishroka H. Intracranial aneurysms and subarachnoid hemorrhage: a co-operative study. Philadelphia: J.B. Lippincott, 1969.

16. Barnet HJM. Some clinical feactures of intracranial aneurysms. Clin Neurosurg 1969;16:43-72.

17. Hook O, Norlen G. Aneurysms of the middle cerebral artery. Acta Cirurg Scand 1958;235:1-39.

18. Kamrin R. Temporal lobe epilepsy caused by unruptured middle cerebral artery aneurysms. Arch Neurol 1966;14:421-427.

19. Kollmann H. Thrombotic aneurysm as the cause of a cerebral seizure: operation and cure: case report. Wien Med Wochenschr 1984;15:459-461.

20. Tanaka K, Hirayama K, Hattori H, et al. A case of cerebral aneurysm associated with complex partial seizures. Brain Dev 1994;16:233-237.
21. Whittle IR, Allsop JL, Halmagyi GM. Focal seizures: an unusual presentation of giant intracranial aneurysms: a report of four cases with comments on the natural history and treatment. Surg Neurol 1985;24:533-540.

22. Locksley HB. Report on the cooperative study of intracranial aneurysms and subarachnoid hemorrhage: natural history of subarachnoid hemorrhage, intracranial aneurysms and arteriovenous malformations. J Neurosurg 1966;25:321-368.

23. Locksley HB. Report on the cooperative study of intracranial aneurysms and subarachnoid hemorrhage: natural history of subarachnoid hemorrhage, intracranial aneurysms and arteriovenous malformations. J Neurosurg 1966;25:219-239.

24. Morley TP, Barr HWK. Giant intracranial aneurysm: diagnosis, cause and management. Clin Neurosurg 1968;16:73-94.

25. Liang-fu Z, Da-jie J. Large and giant intracranial aneurysms: diagnosis and surgical treatment. Chin Med J 1987;100:392-397.

26. Sengupta RP, Sauders M, Clarke PRR. Unruptured intracranial aneurysms: an unusual source of epilepsy. Acta Neurochir 1978;40:45-53.

27. Baeesa SS, Dang T, Keene DL, Ventureyra EC. Unusual association of intractable temporal lobe seizures and intracranial aneurysms in an adolescent: is it a coincidence? Pediatr Neurosurg 1998;28:198-203.

28. Ellamushi H, Thorne L, Kitchen N. Unruptured cerebral aneurysm causing seizure disorder (report of two cases). Seizure 1999;8:310-312.

29. McCulloch DK, Ashworth B. Cerebral aneurysm presenting with epilepsy. Postgraduate Med J 1982;58:94-97.

30. Merva W, Jamshidi S, Kurtzke JF. Posterior communicating artery giant aneurysm as a cause of seizures. Neurology 1985;35:620-622.

31. Pasqualin A, Da Pian R, Colamaria V, Bardin PG. Giant unruptured aneurysm of the middle cerebral artery manifesting with epilepsy. J Neurosurg Sci 1979;23:303-310.

32. Falconer MA,Serafetimides EA, Corsellis JAN. Etiology and pathogenesis of temporal lobe epilepsy. Arch Neurol 1964;10:233-248.

33. Sutherland GR, King ME, Peerless SJ, Vezina WC, Brown GW, Chamberlain J. Platelet interaction within giant intracranial aneurysm. J Neurosurg 1982;10:53-61.

34. Hart RG, Byer JA, Slaughter JR, Hewett JE, Easton JD. Ocurrence and implications of seizures in subarachnoid hemorrhage due to ruptured intracranial aneurysms. Neurosurgery 1981;8:417-421.

35. Mularek O, Owsianowski M. Subarachnoid haemorrhage as a consequence of the epileptic status. Neurol Neurochir Pol 1970;4:475-478.

36. Kolasa P, Palka Z, Skrzydlewska K. Giant brain aneurysm: difficulties in diagnosis and treatment. Case report. Neurol Neurochir Pol 2000;34:35-40.

37. Leibrock LG, Bennett DR, Bloch S. Complex partial seizures associated with unruptured thrombosed basilar artery apex aneurysm. Surg Neurol 1983;19:17-20.

38. Stewart RM, Sanson D, Diehl J, Hinton R, Ditmore QM. Unruptured cerebral aneurysms presenting as recurrent transient neurologic deficits. Neurology 1980;30:47-51.

39. Miyagi J, Shigemori M, Sugita Y, Nishio N, Harada K, Kuramoto S. Giant aneurysm of the middle cerebral artery presenting with complex partial seizure: case report. Neurol Med Chir 1991;31:953-956.

40. Yacubian EMT, Rosemberg S, Silva HCA, Jorge CL, Oliveira E, Assis LM. Intracranial complex partial seizures associated with posterior cerebral artery giant aneurysm: a case report. Epilepsy 1994;35:1317-1320.

41. Provenzale JM, Gorecki JP, Koen JL, Cerebral aneurysms associated with seizures but without clinical signs of rupture: MR imaging findings in two patients. AJR 1996;167:230-232. 